\title{
BMJ Open Factors associated with adverse drug reaction occurrence and prognosis, and their economic impacts in older inpatients in Taiwan: a nested case- control study
}

\author{
Pei-Ju Liao, ${ }^{1}$ Chien-Tai Mao, ${ }^{2}$ Tun-Liang Chen, ${ }^{2}$ Shin-Tarng Deng, ${ }^{2}$ \\ Kuang-Hung $\mathrm{Hsu}^{\odot 3,4,5,6,7}$
}

To cite: Liao P-J, Mao C-T, Chen T-L, et al. Factors associated with adverse drug reaction occurrence and prognosis, and their economic impacts in older inpatients in Taiwan: a nested case-control study. BMJ Open 2019;9:e026771. doi:10.1136/ bmjopen-2018-026771

- Prepublication history and additional material for this paper are available online. To view please visit the journal online (http://dx.doi.org/10.1136/ bmjopen-2018-026771)

Received 21 September 2018 Revised 27 February 2019 Accepted 15 April 2019
Check for updates

(C) Author(s) (or their employer(s)) 2019. Re-use permitted under CC BY-NC. No commercial re-use. See rights and permissions. Published by BMJ.

For numbered affiliations see end of article.

Correspondence to Dr. Kuang-Hung Hsu; khsu@mail.cgu.edu.tw

\section{ABSTRACT}

Objective Older patients are likely to have higher disease complexity and more drug prescriptions of which are associated with a higher incidence of adverse drug reactions (ADR). This study aimed to investigate factors associated with ADR occurrence, prognosis and medical expenses in older inpatients.

Design A nested case-control study.

Setting A medical centre located in north Taiwan. Participants 539 reported ADR cases from a patient cohort containing 108548 older inpatients were collected from 2006 to 2012. There were 1854 non-ADR matched controls; a maximum of 1:5 matched by age, sex and principal diagnosis were collected.

Exposure Polypharmacy, the number of drugs prescribed, comorbidities and the admission department were factors associated with ADRs, as well as subsequent poor prognosis, length of stay and medical expenses.

Primary and secondary outcome measures ADR occurrence and poor prognosis (mortality, discharge against medical advice in critical conditions, or admitted to intensive care unit) were the primary outcomes. Additional medical expenses and the length of hospital stay were the secondary outcomes.

Results The admission department, number of comorbidities and number of drug prescriptions before ADRs were associated with ADR occurrence among older inpatients. ADR severity was a significant prognostic factor among ADR cases. The multivariate-adjusted $\mathrm{OR}$ of 1.63 (95\% Cl 1.36 to 1.95) for poor prognosis was found as the number of comorbidities increased. Patients prescribed $\geq 11$ drugs including psychoactive drugs showed 2.45 -fold ( $95 \% \mathrm{Cl} 1.40$ to 4.28 ) poorer prognosis than other patients. ADRs caused the addition of US $\$ 1803.8$, US $\$ 360.8$ and 5.6 days in total medical expenses, drug expenses and length of stay among affected older inpatients, respectively.

Conclusions The number of comorbidities and polypharmacy including the use of psychoactive drugs has significant impacts on ADR occurrence and prognosis among older inpatients. The findings provide clues for future prescription modification and patient's safety improvement in geriatric care.
Strengths and limitations of this study

- A significant association was found between the number, but not the classes, of drugs prescribed before adverse drug reaction (ADR) occurrence.

- The number of comorbidities played a greater role in developing poor prognosis from ADRs in older inpatients than did the number of prescribed drugs.

- Patients prescribed $\geq 11$ drugs showed 2.45 -fold greater risk in developing poor prognosis.

- We should be cautious when applying the results to other ethnic groups with different genetic backgrounds, patient profile and healthcare systems.

- The medical characteristics of outpatients may differ from the present inpatient findings in terms of disease complications, drug prescriptions and patient's compliance.

\section{INTRODUCTION}

As ageing has become a worldwide phenomenon, geriatric health issues deserve more attention. Previous studies have shown that approximately $55 \%-98 \%$ of patients aged over 65 years have had two or more concurrent diseases. ${ }^{1}$ Multimorbidity and physical frailty in older adults are associated with an elevated risk of death, disability, poor quality of life and adverse drug reactions (ADR). ${ }^{2-4}$ Therefore, the interactive effects of multimorbidity and drug medications need to be continually investigated.

Several studies have revealed that the incidence of ADRs in hospitalised older patients ranged from $6 \%$ to $26 \%$ in different countries. $^{5-7}$ Hospitalised older patients are usually frail and have comorbid conditions that magnify the complexity of healthcare needs and result in unavoidable multiple medication regimens. As a result, accompanied with advancing age, the dysregulation of 
body systems and changes in pharmacokinetics and pharmacodynamics make older patients more susceptible to adverse drug effects. ${ }^{78}$

Using different study populations, the organ systems most frequently affected by ADRs were the dermatological, gastrointestinal, cardiovascular, endocrine and metabolic, and renal systems. ${ }^{5-11}$ A previous study revealed that an additional US $\$ 177.4$ billion spent in the USA was attributable to ADRs in the year 2000. ${ }^{12}$ The prolonged length of stay and extra medical costs caused by an ADR were approximately 1.2-3.8 days and accounted for US\$2284-US\$5456, respectively. ${ }^{13}$ Many studies have documented risk factors, including age, gender, comorbidities, polypharmacy, inappropriate use of drugs, poor cognitive function, alcohol intake, length of stay and depression, as associated with ADRs. ${ }^{14-18}$

However, lifestyle, food style, medical-seeking behaviours and healthcare systems in Asian countries are quite different from western countries. In this sense, the genetic characteristics and susceptibility to drugs, and prescription behaviours were also different in various ethnic groups. For example, the study setting is under a compulsory national health insurance system in which patients are usually seeking multiple medical assistances including western medicine, herbal medicine and food supplements at an affordable cost. Therefore, the characteristics and factors associated with ADRs and the subsequent medical and economic impacts are anticipated to be different.

ADRs contribute to lengthened hospital stays, increased medical expenses and, most importantly, decreased care quality and safety. ${ }^{5}{ }^{11-13}$ Because older inpatients are more likely to have multiple conditions and chances for ADRs, ADR issues in older individuals are worthy of attention. Although many studies have documented risk factors of ADR occurrence, most of the study samples were from western populations. ${ }^{714}$ Due to the differences in ethnicity and healthcare systems, an investigation of Asian ethnicities with a large series of cases is warranted. This study aimed to examine factors associated with ADRs, and the impacts of these factors on prognosis and medical expenses among older inpatients in an Asian population.

\section{METHODS}

\section{Reporting system and data files}

The data were collected from Chang Gung Memorial Hospital (CGMH), a 4000-bed medical centre located in northern Taiwan that serves 3.2 million outpatients, 160000 emergency patients and 120000 inpatients (approximately 1.2 million inpatient-days) each year. CGMH initiated a reporting system for ADRs in 2002 and mandated all medical personnel to report any suspected ADR cases. After a series of administrative interventions, the reporting system is reliable and comprehensive. An ADR case was approved by senior pharmacists and possible challenges were made to confirm the causality of the reported ADRs and a suspicious drug. The number of reported ADR cases was found to plateau and stabilise by the end of 2004. ${ }^{10}$ Under review, monitoring and approval by the Institute Review Board (IRB No: 102-0710C), this study retrospectively collected all reported ADR cases from 1 January 2006 to 31 December 2012 as primary sources from study subjects. During this study period, there were a total of 108548 older inpatients at the study hospital. Among them, a total of 670 in-hospital newly reported ADR cases, an incidence rate of $0.62 \%$, were found. The matched controls were selected according to their similar age ( \pm 3 years), and identical sex and principal diagnosis, with 1:5 matching strategy of up to five non-ADR counterparts for each reported ADR case. Accordingly, 131 reported ADR cases failed to have at least one matched control. Consequently, 539 reported ADR older inpatients were eligible and a total of 1854 matched controls were collected in this nested case-control study (figure 1). No significant difference was found in distributions of sex, age, principal diagnosis, Naranjo score and Charlson Comorbidity Index (CCI) between 539 matched and 131 non-matched ADR cases (data not shown). The sample size was calculated and satisfied under $\mathrm{OR}=2.0$ with a statistical power of 0.8 , assuming a significance level of 0.05 using Power Analysis and Sample Size (PASS V.11, NCSS 2010).

\section{Research variables}

In this study, an ADR was defined according to the definition made by Edwards and Aronson. ${ }^{19}$ An ADR is an appreciably harmful or unpleasant reaction, resulting from an intervention related to the use of a medicinal product, which predicts hazard from future administration and warrants prevention or specific treatment, alteration of the dosage regimen or withdrawal of the product. ${ }^{19}$ Study data were extracted from the reporting system of the focal hospital. Exposure variables included the admission department, patient's age and sex, principal diagnosis, $\mathrm{CCI},{ }^{20}$ comorbidities in terms of the number of secondary diagnoses and number of drugs prescribed before ADR inception. Additionally, the Naranjo score was assigned by senior pharmacists trained and standardised before practice. The Charlson score was calculated retrospectively from the claim database. For non-ADR cases, the number and classes of drugs prescribed within the same timespan on admission compared with that of the matched ADR case was calculated. ADR-related variables included suspicious drugs, affected organs, symptoms or syndromes of ADRs, the Naranjo score ${ }^{21}$ and the severity of the ADRs. The symptoms and signs of the ADRs were categorised into 13 groups according to the affected organs and systems (online supplementary appendix 1 ). The suspicious drugs causing ADRs were grouped into 15 classes, including others, according to their pharmacological and anatomical-physiological characteristics (online supplementary appendix 2). The identification of drugs was based on the different chemical names and coded by the Anatomical Therapeutic Chemical classification system. ${ }^{22}$ 


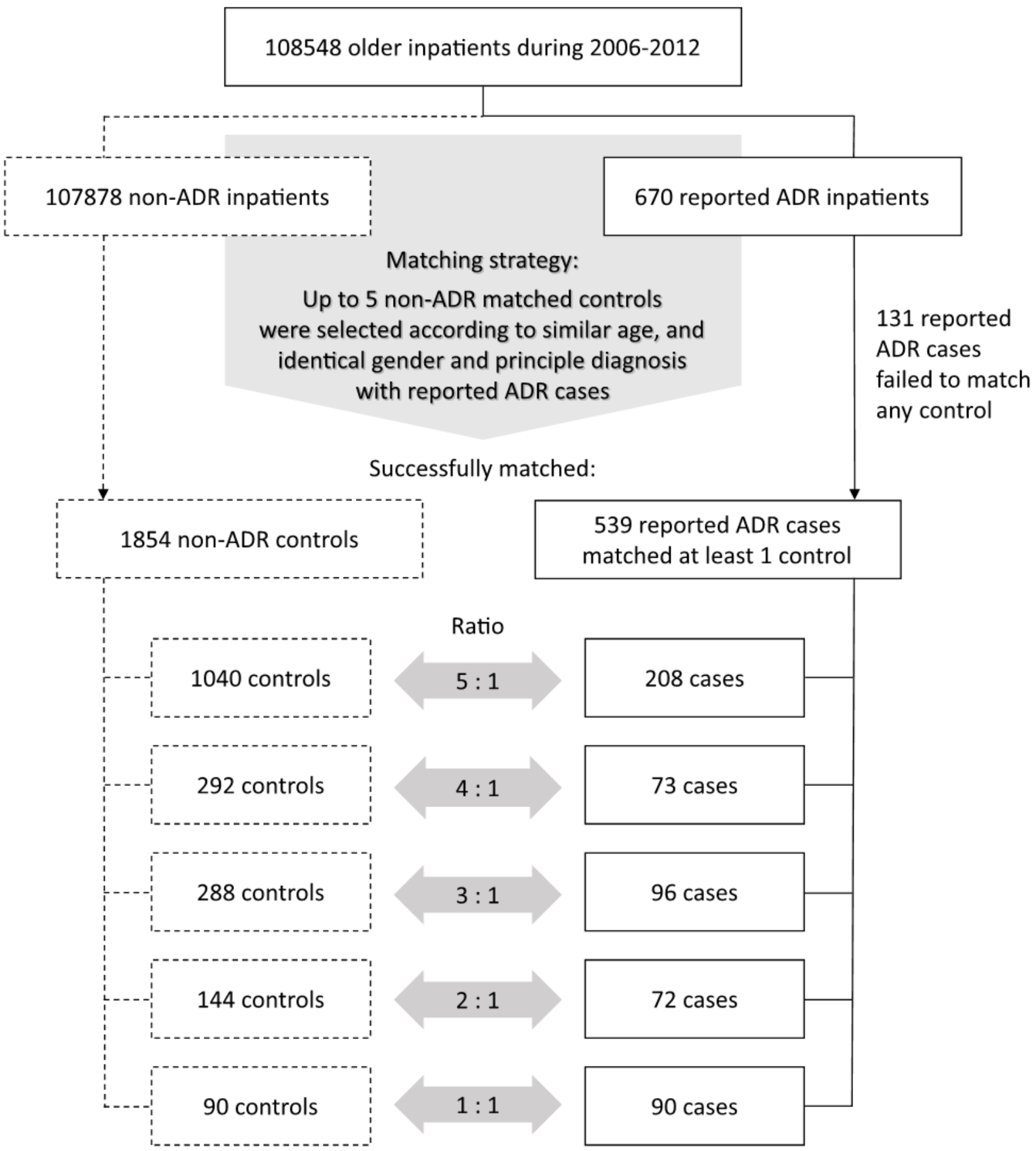

Figure 1 Flow diagram for case-control matching. ADR, adverse drug reaction. 
The primary outcomes of this study are ADR occurrence and the prognosis of the study inpatients. The prognoses were recorded from discharge conditions, which were classified as poor (including deaths, discharge against medical advices in critical conditions and continued hospitalisation to intensive care unit (ICU) ) and improved status (including recovery and outpatient follow-up). Additional medical expenses during hospitalisation and the length of hospital stay were the secondary outcomes.

\section{Statistical methods}

Descriptive statistics were used to examine the distribution of the variables between the case and control groups. Categorical variables are presented as the frequency and percentage, whereas numerical variables were presented as the means and SDs. Univariate analyses were applied to determine the significance of the variables as preliminary information for further analyses. Categorical variables were analysed using the $\mathrm{X}^{2}$ test to compare groups, whereas numerical variables were tested with two-sample t-tests between groups. Multiple logistic regression analysis was used to construct models for the occurrence and prognosis of ADRs. For the model selection, variables with $p$ value $<0.2$ were considered as candidates for multivariable analyses. A backward selection method was applied in this study. The OR was calculated as the strength of association in modelling the ADR occurrence and poor prognoses. A generalised linear model was applied to estimate the length of hospital stays and medical expenses, and a logarithmic transformation was performed with positive skewing. All statistical analyses were performed using SAS V.9.4.

\section{Patient and public involvement}

There was no patient or public involvement in the study.

\section{RESULTS}

The study collected 539 reported ADR cases from older inpatients at the medical centre during the period of 2006-2011. A total of 1854 matched control older inpatients without reported ADRs were sampled. The mean age of the ADR cases and controls was close to 76 years old (table 1). Male inpatients accounted for $55.8 \%$ of the study samples. The highest incidence of reported ADRs among the older inpatients was in the department of internal medicine $(57.7 \%)$, followed by those in surgery $(15.8 \%)$, oncology (11.9\%) and infectious diseases $(8.5 \%)$. A significant association was found between the admission department and the reported ADR occurrence $(p=0.0079)$. The top three frequently seen principal diagnoses in reported ADR cases were respiratory diseases $(21.7 \%)$, circulation system $(16.9 \%)$ and neoplasms (13.0\%). The reported ADR cases had an increased number of comorbidities, and $13.2 \%$ of the cases had five or more comorbidities, as opposed to $0.6 \%$ in the control group ( $\mathrm{p}<0.0001)$. The CCI distribution was not associated with the reported ADR occurrence (table 1).
Regarding the ADR characteristics, the Naranjo score, as rated by senior pharmacists, was recorded to reflect the causality of the reported ADR cases. A total of 451 cases $(83.7 \%)$ were scored as $\leq 4,83$ cases $(15.4 \%)$ as $5-8$, and 5 cases $(0.9 \%) \geq 9$ (table 2$)$. A total of $317(58.8 \%)$ cases were rated as moderate severity followed by $192(35.6 \%)$ as mild, and $30(5.6 \%)$ as severe. The outcome measure of poor prognosis, including death, discharge against medical advice in critical conditions and continued hospitalisation to ICU, as identified according to discharge notes, was reported more frequently in patients experiencing ADRs (18.7\%) than the control patients (11.5\%) $(\mathrm{p}<0.0001)$. Both reported ADR and non-ADR groups were prescribed approximately 15 classes of drugs before ADR inception during their entire hospital stay, though a significant difference was shown between the two groups ( $\mathrm{p}=0.0069$ and $\mathrm{p}<0.0001$, respectively). The number of drug prescriptions before ADRs was higher in the ADR group (106.16) than in the non-ADR group (98.96) $(p<0.0001)$. Higher medical expenses were accrued in the reported ADR group compared with the non-ADR control group. The length of hospital stay for the reported ADR inpatients averaged 30.8 days longer than the average of 16.9 days for the control group $(\mathrm{p}<0.0001)$. Analysis of the total medical expenses showed that medical expenses were US $\$ 9531.3$ for ADR inpatients compared with US $\$ 4108.9$ for the control group $(\mathrm{p}<0.0001)$. Drug medication expenses were US\$2276.4 in the reported ADR group, which was significantly higher than that in the control group (US\$817.0; $\mathrm{p}<0.0001$ ) (table 2 ).

The multivariate analyses showed that the department of oncology had a higher likelihood of reporting ADR occurrence $(\mathrm{OR}=1.71 ; 95 \%$ CI 1.10 to 2.67$)$ than the reference department, infectious disease department (model 1 in table 3). A dose-response relationship was found between the number of comorbidities and the reported ADR occurrence, with an OR of 1.43 (95\% CI 1.29 to 1.57$)$ for each increment of comorbidity. The likelihood of reported ADR occurrence was significantly increased as the number of drug prescriptions before ADR increased ( $\mathrm{OR}=1.02$, 95\% CI 1.01 to 1.02 , for each increment).

Furthermore, reported ADR cases being prescribed $\geq 11$ anticonvulsants, antipyretics, narcotic analgesics, tranquillisers, sedates and hypnotics, or other central nervous system (CNS) drugs were at a higher risk of having poor prognosis $(\mathrm{OR}=2.45,95 \%$ CI 1.40 to 4.28$)$ than those prescribed $<11$ prescriptions. The degree of reported ADR severity was positively associated with poor prognoses ( $<<0.05$, test for monotonic trend) in which reported ADR cases with moderate and severe severity were at a higher risk of poor prognosis $(\mathrm{OR}=1.95,95 \%$ CI 1.12 to 3.42 and $\mathrm{OR}=2.74,95 \%$ CI 0.98 to 7.72 , respectively) than those with mild severity (model 2 in table 3 ).

Multivariable-adjusted estimates of economic impacts, including total medical expenses, drug expenses and length of hospital stay, by reported ADR severity are presented in figure 2. ORs were used to demonstrate the 
Table 1 Demographic and clinical characteristics of the study subjects

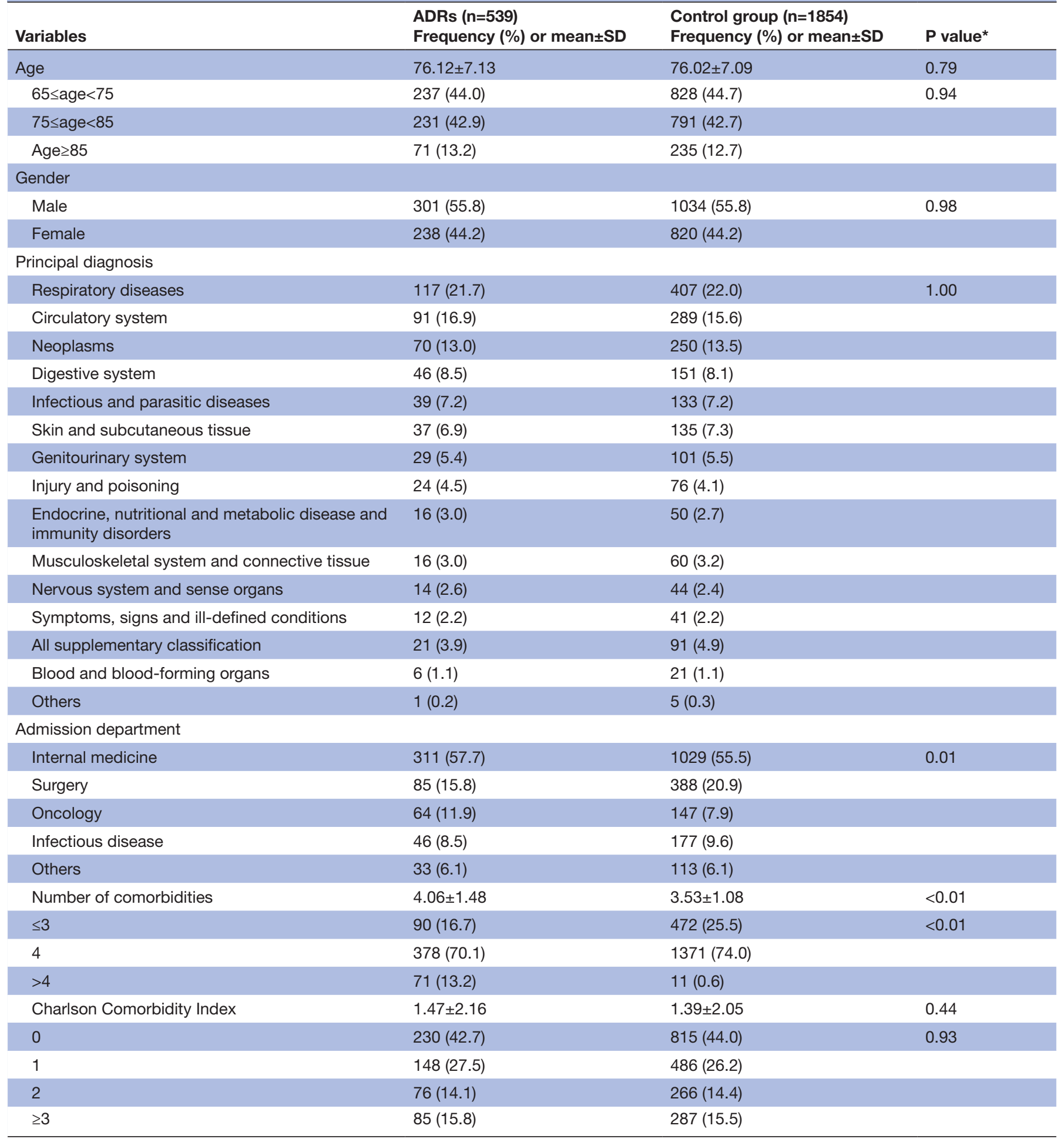

${ }^{*} \mathrm{P}$ value was acquired from $\mathrm{X}^{2}$ tests for categorical variables and t-test for continuous variables.

ADR, adverse drug reaction.

relative increase in medical consumption. Total medical expenses and drug expenses followed a dose-response relationship with the degree of reported ADR severity and a significantly monotonic trend was observed. The additional US $\$ 1512.7-U S \$ 4141.6$ and US $\$ 317.9-U S \$ 593.8$ costs derived from incremental reported ADR severity were found for the total medical expenses and drug expenses, respectively, during hospitalisation (data not shown). The relative increase in the length of hospital stay was higher among reported ADR cases (data not shown; fold elevation $=1.45 ; 95 \%$ CI 1.34 to 1.56 ) as opposed to non-ADR controls. 
Table 2 The ADR characteristics, prognosis and medical consumptions of study subjects

\begin{tabular}{|c|c|c|c|}
\hline Variables & $\begin{array}{l}\text { ADRs }(n=539) \\
\text { Frequency }(\%) \text { or mean } \pm \text { SD }\end{array}$ & $\begin{array}{l}\text { Control group }(n=1854) \\
\text { Frequency }(\%) \text { or mean } \pm \text { SD }\end{array}$ & $P$ value \\
\hline \multicolumn{4}{|l|}{ Naranjo score } \\
\hline Possible $(\leq 4)$ & $451(83.7)$ & & \\
\hline Probable (5-8) & $83(15.4)$ & & \\
\hline Definite $(\geq 9)$ & $5(0.9)$ & & \\
\hline \multicolumn{4}{|l|}{ Severity } \\
\hline Mild & $192(35.6)$ & & \\
\hline Moderate & $317(58.8)$ & & \\
\hline Severe & $30(5.6)$ & & \\
\hline \multicolumn{4}{|l|}{ Prognosis } \\
\hline Discharge & $438(81.3)$ & $1640(88.5)$ & $<0.01$ \\
\hline Continued hospitalisation & $21(3.9)$ & $45(2.4)$ & \\
\hline Death & $80(14.8)$ & $169(9.1)$ & \\
\hline \multicolumn{4}{|c|}{ Drug prescriptions before ADR inception } \\
\hline Classes* & $14.82 \pm 0.43$ & $14.76 \pm 0.58$ & $<0.01$ \\
\hline Numbert & $106.16 \pm 19.85$ & $98.96 \pm 20.01$ & $<0.01$ \\
\hline \multicolumn{4}{|c|}{ Drug prescriptions during the whole hospital stay } \\
\hline Classes* $^{*}$ & $14.98 \pm 0.14$ & $14.95 \pm 0.22$ & $<0.01$ \\
\hline$<13$ & $0(0.0)$ & $16(0.9)$ & 0.08 \\
\hline 13 & $10(1.9)$ & $39(2.1)$ & \\
\hline 14 & $75(13.9)$ & $302(16.3)$ & \\
\hline 15 & $454(84.2)$ & $1497(80.7)$ & \\
\hline Number† & $113.91 \pm 15.44$ & $112.86 \pm 15.51$ & 0.16 \\
\hline \multicolumn{4}{|l|}{ Medical consumptions } \\
\hline Length of stay (days) & $30.8 \pm 30.2$ & $16.9 \pm 14.7$ & $<0.01$ \\
\hline Total medical expenses (US\$) & $9531.3 \pm 13634.5$ & $4108.9 \pm 5180.1$ & $<0.01$ \\
\hline Drug expenses (US\$) & $2276.4 \pm 4244.1$ & $817.0 \pm 1806.8$ & $<0.01$ \\
\hline
\end{tabular}

${ }^{*}$ Classes of drug prescriptions according to Anatomical Therapeutic Chemical (ATC) classification (online supplementary appendix 2). †Number of drug prescriptions according to different ATC codes.

ADR, adverse drug reaction.

\section{DISCUSSION}

ADRs have become an important healthcare issue in the older population, particularly for the fast-growing aged population in Asia-Pacific countries. Although a relatively lower percentage of ADR cases was observed in this study population due to attributes associated with ethnicity and the healthcare system, the findings provide clues for improving patient safety and reducing medical costs that are valuable for a professional society in the world. This study identified factors associated with the occurrence and consequences of ADRs among older inpatients. The study found that the patient's admission department, number of comorbidities and number of drug prescriptions before ADRs were associated with both the occurrence and prognosis of ADRs. In addition to the association between polypharmacy and ADRs, the study has demonstrated that an increased number of CNS-related drug prescriptions and the degree of ADR severity were associated with poor prognosis in patients. Furthermore, a dose-response relationship was found between ADR severity and total medical expenses and drug expenses. This study enriched the body of knowledge on drug-related problems for older inpatients in Taiwan.

The effects of age-related physiological alterations, as well as the presence of comorbidity and polypharmacy, have been previously reported. ${ }^{82} 24$ Ageing involves gradual impairments in multiple organs and physiological changes such as decreases in both hepatic and renal blood flow, and glomerular filtration rates that lead to less than favourable pharmacokinetic consequences. ${ }^{23}{ }^{25}$ Interactions between altered kinetics and reduced homeostatic response also complicate pharmacodynamics in older individuals. Therefore, modified prescription guidelines should be considered for older patients. Additionally, current therapeutic decisions usually focus on specific diseases and seldom consider complicated comorbid 
Table 3 The factors associated with the occurrence of ADRs and poor prognosis in older inpatients

\begin{tabular}{|c|c|c|}
\hline & Model 1† & Model 2‡ \\
\hline & $\begin{array}{l}\text { ADR occurrence } \\
(n=2393)\end{array}$ & $\begin{array}{l}\text { Poor prognoses } \S \text { in ADR cases } \\
(n=539)\end{array}$ \\
\hline Variables & OR $(95 \% \mathrm{Cl})$ & OR $(95 \% \mathrm{Cl})$ \\
\hline \multicolumn{3}{|l|}{ Admission department } \\
\hline Infectious disease & 1.00 & 1.00 \\
\hline Internal medicine & $1.15(0.81$ to 1.64$)$ & $4.16(1.10 \text { to } 15.71)^{\star}$ \\
\hline Surgery & $0.98(0.65$ to 1.48$)$ & $5.12(1.18 \text { to } 22.21)^{\star}$ \\
\hline Oncology & $1.71(1.10 \text { to } 2.67)^{\star}$ & $1.14(0.22$ to 6.01$)$ \\
\hline Others & $1.63(0.96$ to 2.76$)$ & $3.22(0.51$ to 20.09$)$ \\
\hline \multicolumn{3}{|l|}{ Principal diagnosis } \\
\hline $\begin{array}{l}\text { Skin and subcutaneous tissue, } \\
\text { musculoskeletal system and } \\
\text { connective tissue }\end{array}$ & & 1.00 \\
\hline Infectious and parasitic diseases & & $3.64(0.86$ to 15.45$)$ \\
\hline Respiratory diseases & & $3.21(0.83$ to 12.40$)$ \\
\hline Neoplasms & & $5.78(1.38 \text { to } 24.18)^{*}$ \\
\hline Injury and poisoning & & $0.77(0.10$ to 5.69$)$ \\
\hline Circulatory system & & 2.19 (0.56 to 8.58$)$ \\
\hline Digestive system & & $3.12(0.73$ to 13.37$)$ \\
\hline Genitourinary system & & $1.49(0.26$ to 8.70$)$ \\
\hline $\begin{array}{l}\text { Endocrine, nutritional and metabolic } \\
\text { disease and immunity disorders }\end{array}$ & & $0.59(0.05$ to 7.10$)$ \\
\hline Nervous system and sense organs & & $2.03(0.29$ to 14.14$)$ \\
\hline Others & & $0.88(0.12$ to 6.23$)$ \\
\hline Comorbidities, $n$ & $1.43(1.29 \text { to } 1.57)^{*}$ & $1.63(1.36 \text { to } 1.95)^{*}$ \\
\hline $\begin{array}{l}\text { Drug prescriptions before ADR } \\
\text { inception } \dagger \dagger, n\end{array}$ & $1.02(1.01 \text { to } 1.02)^{*}$ & \\
\hline \multicolumn{3}{|l|}{$\begin{array}{l}\text { Prescriptions of anticonvulsants, } \\
\text { antipyretics, narcotic analgesics, } \\
\text { tranquillisers, sedates and hypnotics, } \\
\text { other CNS drugsł‡ }\end{array}$} \\
\hline$<11$ & & 1.00 \\
\hline$\geq 11$ & & $2.45(1.40 \text { to } 4.28)^{\star}$ \\
\hline \multicolumn{3}{|l|}{ ADR severity } \\
\hline Mild & & $1.00^{* *}$ \\
\hline Moderate & & $1.95(1.12 \text { to } 3.42)^{\star}$ \\
\hline Severe & & $2.74(0.98$ to 7.72$)$ \\
\hline
\end{tabular}

${ }^{*} \mathrm{P}<0.05 ;{ }^{* *} \mathrm{P}<0.05$, test for monotonic trend.

†Model 1 adjusted for admission department, number of comorbidities and number of drug prescriptions before ADR inception. $\ddagger$ Model 2 adjusted for admission department, principal diagnosis, number of comorbidities, ADR severity and prescriptions of anticonvulsants, antipyretics, narcotic analgesics, tranquillisers, sedates and hypnotics, and other CNS drugs.

§oor prognoses include deaths, discharge against medical advices in critical conditions and continued hospitalisation to intensive care unit (ICU).

IThis includes symptoms, signs and ill-defined conditions; blood and blood-forming organs; all supplementary classification; and all other diagnoses.

††For non-ADRs, this was the accumulated number of drug prescriptions during the same period of time on admission to the time of ADR occurrence in the matched cases.

抽is includes antiparkinsonism, general anaesthetics, antidepressants and central nervous system (CNS) stimulants. The median is 11 prescriptions in this drug category.

ADR, adverse drug reaction. 
3.50

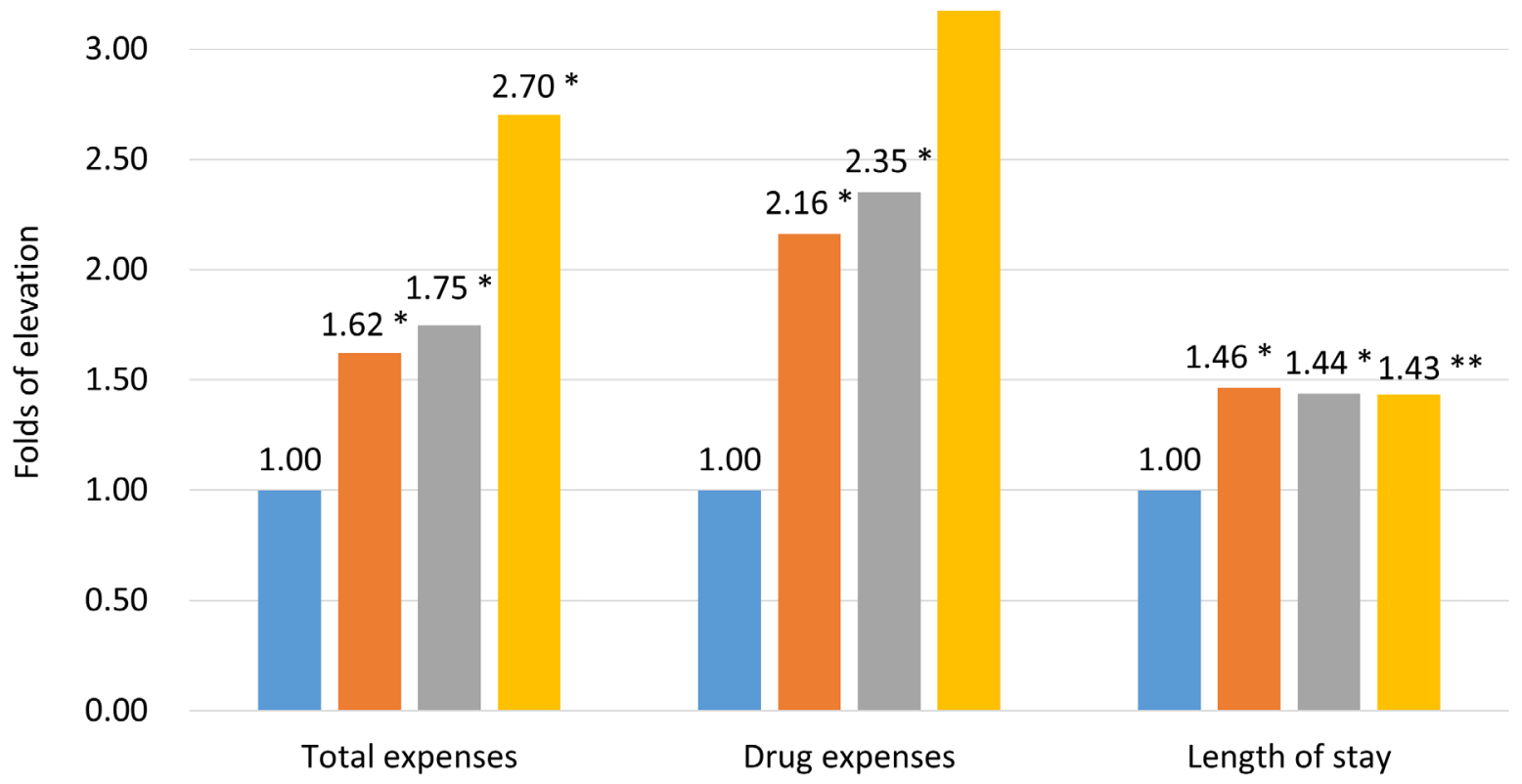

Non-ADRs Mild severity

Moderate severity $\quad$ Severe severity

Figure 2 Relative elevation in medical consumption among different ADR severities compared with that of non-ADRs, adjusting for principal diagnosis, admission department, number of comorbidities and classes of drug prescriptions during hospitalisation. ${ }^{*} P<0.0001$ and ${ }^{* *} P<0.01$. Tests for monotonic trends for total expenses and drug expenses were significant at the $p<0.0001$ level. ADR, adverse drug reaction.

conditions. Altogether, these factors make older patients at a greater risk for ADRs. In the present study, $76.5 \%$ of older inpatients had four or more comorbidities, in which interactions with the number of drug prescriptions were found. This study also found a synergistic effect between the number of comorbidities and ADR occurrence on poor prognosis, which suggests that patients' physiological responses to drugs and disease complexity are inter-related. While most studies demonstrated specific drug classes as a cause of ADRs, ${ }^{26-28}$ our study, in particular, found that numerous CNS-related prescriptions are likely to cause poor prognosis among older inpatients. A conjecture of older specific health problems and high-risk characteristics is made for future geriatric care. Poor prognosis in older patients was associated with ADR severity, which depicts the vulnerability of older patients to adverse drug events. Prevention and intervention in the misuse of polypharmacy in older patients may be as important as preventing infectious diseases such as pneumonia in the future.

The CCI and number of comorbidities have been used in parallel to examine the association with ADR occurrence in this study. However, the CCI was not significantly associated with ADR occurrence in this analysis. The possible reasons for the inconsistency may be attributable to the CCI calculation only including selected diagnoses rather than all present diseases. Instead of applying CCI, several studies documented the impacts of specific comorbidities, such as renal insufficiency, congestive heart failure and diabetes on the risk of ADRs. ${ }^{729} 30$ Unfortunately, there is no universal algorithm to date. However, an easier way of counting the comorbidities is currently accepted and applicable. Onder et al have demonstrated that patients with more than four comorbidities had an elevated risk of ADR occurrence. ${ }^{6}$ Another study has also demonstrated a positive association between the number of secondary diagnoses and the risk of developing cutaneous ADRs among inpatients. ${ }^{10}$ Our study demonstrated consistently that the number of comorbidities can predict ADR occurrence and the subsequent prognosis. This is a critical indicator in modifying medical treatments for the older population.

This study confirmed the positive association between the number of drugs prescribed before ADRs and ADR inception. ${ }^{631}$ Various studies have demonstrated that the number or classes of drug prescriptions was positively 
associated with the occurrence of ADRs among various inpatients, with the ORs ranging from 1.09 to $3.3 .{ }^{531-33}$ The present study has demonstrated a significant association between the number, but not the classes, of drugs prescribed before ADRs and ADR occurrence (model 1 in table 3). The underlying mechanisms could be high drug dose exposure or a high chance of possible drug-drug interactions, even in the same drug class. In our analysis, a relatively lower strength of association was found for the number of drugs $(\mathrm{OR}=1.02)$ compared with the number of comorbidities $(\mathrm{OR}=1.43)$, which was consistent with previous observations that patient physiological and functional characteristics are more important for predicting both adverse and beneficial outcomes. ${ }^{34}$ Previous articles have reported the prevalence of multimorbidity among older populations in North America and Australia ranging from $53.9 \%$ to $98.7 \% .^{35} 36$ To manage coexistent diseases, multiple medications are a common practice, and the risk of ADRs is simultaneously elevated.

The oncology department was identified as the admitting department with the greatest likelihood for patients to develop ADRs. Previous studies have suggested that some antineoplastic agents are associated with a higher risk of developing ADRs. ${ }^{6}$ According to our analysis of drug classes that caused ADRs, the top three classes are antibiotics (293, 54.36\%); anticonvulsants, antipyretics, narcotic analgesics, tranquillisers, sedates and hypnotics, and other CNS drugs $(55,10.20 \%)$; and antineoplastic agents $(50,9.28 \%$ ) (online supplementary appendix 2 ). Aside from antineoplastic agents, the other two classes of drugs are commonly prescribed across different admission departments, including the oncology department. Whether potentially harmful drug-drug interactions may increase the likelihood of ADRs in complicated patients in the oncology department is worthy of further investigations.

With regard to the adverse impacts of ADRs on prognosis, the mortality rate of older inpatients with ADRs was calculated to be $14.8 \%$, which was 1.6 -fold higher than the controls (9.1\%) (table 2). Based on multivariable-adjusted logistic regression, age, principal diagnosis, admission department, comorbidities and specific medications are associated with the development of poor prognosis. Interestingly, ADR severity instead of ADR occurrence was a significant factor of poor prognosis during hospitalisation, which is consistent with other studies. ${ }^{10} 37$

ADRs contributed to significant increases in total medical expenses, drug fees and length of stay. Moreover, US $\$ 1803.8$ and US $\$ 360.8$ per hospitalisation in total medical expenses and drug fees, respectively, were attributable to ADR occurrence (data not shown). Additionally, an extra 5.6 days of hospital stay was found among older ADR inpatients (data not shown), which is higher than that observed in previous studies showing up to $36 \%$ or 3.8 days of additional length of stay due to ADRs among adult inpatients. ${ }^{37-39}$

Polypharmacy is commonly seen in older patients due to multicomorbidity conditions. Special caution should be taken when prescribing older patients with non-antibiotic anti-infective agent, anticonvulsants, antipyretics, narcotic analgesics, tranquillisers, sedates and hypnotics, and other CNS drugs. Rearrangement of prescription dosage plus the intervals of these medicines is expected to reduce the chance of ADRs and improve care quality. Although we have reported a lower percentage of ADRs in this study, lower ADRs were also found in previous studies from the same population. ${ }^{1011}$ We believe that there are a number of reasons that cause the low ADR prevalence in this inpatient cohort. First, we have an information alarm system to assist physicians to reconfirm and avoid ADRs while prescribing a potential drug. Second, the ethnicity difference and cautious prescribing behaviour may cause a low ADR in this medical centre. Third, although we have incentives for physicians, nurses and pharmacists to report ADRs, there might be under-reporting in practice.

\section{Limitations}

Although this study is a representative and comprehensive ADR database analysis at the largest medical centre in Taiwan, some limitations merit our attention. First, the study did not differentiate between preventable and non-preventable ADRs, which might influence the factor inference. Second, the number and classes of drug prescriptions, regarding generic or brand names, are different across healthcare systems, which may affect results of risk analyses focused on ADR occurrence and poor prognosis. Third, caution should be made when applying the results to other ethnic groups with different genetic backgrounds, patient profile and healthcare systems. Moreover, even comparisons made among Asia-Pacific areas should be cautious as Asia is a large, ethnically, culturally and health system-wise heterogeneous area. Fourth, we observed a lower percentage of ADR occurrence among the inpatients when compared with western countries. The factors associated with ADRs and poor prognosis may be different in higher ADR ethnicities and healthcare systems. Finally, the medical characteristics of outpatients may differ from the present inpatient findings in terms of disease complications, drug prescriptions and patient compliance.

\section{Author affiliations}

${ }^{1}$ Department of Health Care Administration, Oriental Institute of Technology, New Taipei City, Taiwan

2Department of Pharmacy, Chang Gung Memorial Hospital, Taoyuan, Taiwan

${ }^{3}$ Department of Health Care Management, and Healthy Aging Research Center, Chang Gung University, Tao-Yuan, Taiwan

${ }^{4}$ Department of Emergency Medicine, Chang Gung Memorial Hospital, Taoyuan, Taiwan

${ }^{5}$ Department of Urology, Chang Gung Memorial Hospital, Taoyuan, Taiwan

${ }^{6}$ Research Center for Food and Cosmetic Safety, College of Human Ecology, Chang Gung University of Science and Technology, Taoyuan, Taiwan

${ }^{7}$ Department of Safety, Health and Environmental Engineering, Ming Chi University of Technology, New Taipei City, Taiwan

Contributors PJL performed the research, analysed and interpreted the data, and revised the manuscript. CTM provided clinical expertise, assisted in data collection and compiling the database, and interpreted the data. TLC assisted in providing clinical expertise and data interpretation. STD assisted in data collection 
and providing clinical expertise. KHH initiated the study, provided the study design, performed the statistical analyses, and wrote and extensively revised the manuscript. All authors have read and approved the final manuscript for publication.

Funding This work was supported by the Ministry of Science and Technology (NSC-98-2410-H-182-011- MY3), and the Healthy Aging Research Center of Chang Gung University (EMRPD1I0431, EMRPD110501). The authors were indebted to the support, in part, provided by the Wang Jhan-Yang Public Trust Fund (WJY 2017-HR01, WJY 2018-HR-01, WJY 2019-HR-01).

Competing interests None declared.

Patient consent for publication Not required.

Ethics approval This study was reviewed, monitored and approved by the Institute Review Board (IRB No: 102-0710C) of Chang Gung Medical Foundation.

Provenance and peer review Not commissioned; externally peer reviewed.

Data sharing statement Will individual participant data be available (including data dictionaries)? Example 4 : Not available. What data in particular will be shared? Example 4 : Not available. What other documents will be available? Example 4 : Not available. When will data be available (start and end dates)? Example 4 : Not available. For what types of analyses? Example 4 : Not available. By what mechanism will data be made available? Example 4 : Not available.

Open access This is an open access article distributed in accordance with the Creative Commons Attribution Non Commercial (CC BY-NC 4.0) license, which permits others to distribute, remix, adapt, build upon this work non-commercially, and license their derivative works on different terms, provided the original work is properly cited, appropriate credit is given, any changes made indicated, and the use is non-commercial. See: http://creativecommons.org/licenses/by-nc/4.0/.

\section{REFERENCES}

1. Marengoni A, Angleman S, Melis R, et al. Aging with multimorbidity: a systematic review of the literature. Ageing Res Rev 2011;10:430-9.

2. Bergman H, Ferrucci L, Guralnik J, et al. Frailty: an emerging research and clinical paradigm--issues and controversies. J Gerontol A Biol Sci Med Sci 2007;62:731-7.

3. Lattanzio F, Landi F, Bustacchini S, et al. Geriatric conditions and the risk of adverse drug reactions in older adults: a review. Drug Saf 2012;35 Suppl 1:55-61.

4. Salive ME. Multimorbidity in older adults. Epidemiol Rev 2013;35:75-83. mxs009..

5. O'Connor MN, Gallagher P, Byrne S, et al. Adverse drug reactions in older patients during hospitalisation: are they predictable? Age Ageing 2012;41:771-6.

6. Onder G, Petrovic M, Tangiisuran B, et al. Development and validation of a score to assess risk of adverse drug reactions among in-hospital patients 65 years or older: the GerontoNet ADR risk score. Arch Intern Med 2010;170:1142-8.

7. Sikdar KC, Dowden J, Alaghehbandan R, et al. Adverse drug reactions in elderly hospitalized patients: a 12-year population-based retrospective cohort study. Ann Pharmacother 2012;46:960-71.

8. Corsonello A, Pedone C, Incalzi RA. Age-related pharmacokinetic and pharmacodynamic changes and related risk of adverse drug reactions. Curr Med Chem 2010;17:571-84.

9. Shah R, Gajjar B, Desai S. A profile of adverse drug reactions with risk factors among geriatric patients in a tertiary care teaching rural hospital in India. Natl J Physiol Pharm Pharmacol 2012;2:113-22.

10. Liao PJ, Shih CP, Mao CT, et al. The cutaneous adverse drug reactions: risk factors, prognosis and economic impacts. Int J Clin Pract 2013;67:576-84.

11. Chan AL, Lee HY, Ho CH, et al. Cost evaluation of adverse drug reactions in hospitalized patients in Taiwan: A prospective, descriptive, observational study. Curr Ther Res Clin Exp 2008;69:118-29.

12. Ernst FR, Grizzle AJ. Drug-related morbidity and mortality: updating the cost-of-illness model. J Am Pharm Assoc 2001;41:192-9.
13. Rodríguez-Monguió R, Otero MJ, Rovira J. Assessing the economic impact of adverse drug effects. Pharmacoeconomics 2003;21:623-50.

14. Zhang M, Holman CD, Price SD, et al. Comorbidity and repeat admission to hospital for adverse drug reactions in older adults: retrospective cohort study. BMJ 2009;338:a2752.

15. Merle L, Laroche ML, Dantoine T, et al. Predicting and preventing adverse drug reactions in the very old. Drugs Aging 2005;22:375-92.

16. Tangiisuran B. Predicting adverse drug reactions in the hospitalised elderly [Doctroal Dissertation]. Brighton, University of Brighton 2009.

17. Passarelli MC, Jacob-Filho W, Figueras A. Adverse drug reactions in an elderly hospitalised population: inappropriate prescription is a leading cause. Drugs Aging 2005;22:767-77.

18. Nguyen JK, Fouts MM, Kotabe SE, et al. Polypharmacy as a risk factor for adverse drug reactions in geriatric nursing home residents. Am J Geriatr Pharmacother 2006;4:36-41.

19. Edwards IR, Aronson JK. Adverse drug reactions: definitions, diagnosis, and management. Lancet 2000;356:1255-9.

20. Charlson M, Szatrowski TP, Peterson J, et al. Validation of a combined comorbidity index. J Clin Epidemiol 1994;47:1245-51.

21. Naranjo CA, Busto U, Sellers EM, et al. A method for estimating the probability of adverse drug reactions. Clin Pharmacol Ther 1981;30:239-45.

22. Methodology WCCfDS. ATC/DDD Index 2017. 2017 https://www. whocc.no/atc_ddd_index/ (22 August 2017).

23. Klotz U. Pharmacokinetics and drug metabolism in the elderly. Drug Metab Rev 2009;41:67-76.

24. Rochon PA, Gurwitz JH. Drug therapy. The Lancet 1995;346:32-6.

25. Schmucker DL. Aging and drug disposition: an update. Pharmacol Rev 1985;37:133-48.

26. laboni A, Fitzgerald P, Rodin G. Special Issues in Psychopharmacology: The Elderly. Psycho Oncol Palliat Care: Springer 2014:349--68.

27. Laroche ML, Charmes JP, Nouaille $Y$, et al. Is inappropriate medication use a major cause of adverse drug reactions in the elderly? Br J Clin Pharmacol 2007;63:177-86.

28. Routledge PA, O'Mahony MS, Woodhouse KW. Adverse drug reactions in elderly patients. Br J Clin Pharmacol 2004;57:121-6.

29. Kane-Gill SL, Kirisci L, Verrico MM, et al. Analysis of risk factors for adverse drug events in critically ill patients. Crit Care Med 2012;40:823-8.

30. Corsonello A, Pedone C, Corica F, et al. Concealed renal insufficiency and adverse drug reactions in elderly hospitalized patients. Arch Intern Med 2005;165:790-5.

31. Trivalle $C$, Burlaud A, Ducimetière P. Risk factors for adverse drug events in hospitalized elderly patients: A geriatric score. Eur Geriatr Med 2011;2:284-9.

32. Field TS, Gurwitz JH, Avorn J, et al. Risk factors for adverse drug events among nursing home residents. Arch Intern Med 2001;161:1629-34.

33. Onder G, Pedone C, Landi F, et al. Adverse drug reactions as cause of hospital admissions: results from the Italian Group of Pharmacoepidemiology in the Elderly (GIFA). J Am Geriatr Soc 2002;50:1962-8.

34. Gurwitz JH, Avorn J. The ambiguous relation between aging and adverse drug reactions. Ann Intern Med 1991;114:956-66.

35. Fortin M, Bravo G, Hudon C, et al. Prevalence of multimorbidity among adults seen in family practice. Ann Fam Med 2005;3:223-8.

36. Caughey GE, Vitry Al, Gilbert AL, et al. Prevalence of comorbidity of chronic diseases in Australia. BMC Public Health 2008;8:221.

37. Classen DC, Pestotnik SL, Evans RS, et al. Adverse drug events in hospitalized patients. Excess length of stay, extra costs, and attributable mortality. JAMA 1997;277:301-6.

38. Bates DW, et al. The costs of adverse drug events in hospitalized patients. JAMA: The Journal of the American Medical Association 1997;277:307-11.

39. Suh DC, Woodall BS, Shin SK, et al. Clinical and economic impact of adverse drug reactions in hospitalized patients. Ann Pharmacother 2000;34:1373-9. 